\title{
Effect of Social Factors on Metabolic Improvement in Type II Diabetic Patients
}

\author{
Wari Yamamoto, Hideki Origasa, Toshio Yaginuma and Yasunori Kanazawa
}

\begin{abstract}
Psychological and social factors can profoundly influence a patient's success in adhering to a prescribed self-care regimen. A total of 34 inpatients with type II diabetes who attended the diabetes education program at a single clinic were studied as a retrospective cohort, beginning between 6 and 12 months after discharge. At the start of the study, the patients were classified into two groups, those with good control and those with poor control of diabetes, based on the rate of change of the glycosylated hemoglobin (HbAlc) value relative to the value at admission. Data for each patient were collected retrospectively from their medical records. Patients' family function was assessed by the adaptability, partnership, growth, affection, and resolve (APGAR) scoring system. Multiple regression analysis was used to determine the effect of demographic, medical, and social factors on metabolic improvement. The family APGAR score was higher in the good control group than in the group with poor control.
\end{abstract}

(Internal Medicine 32: 763-767, 1993)

Key words: family APGAR, diabetes control, patient education

\section{Introduction}

The aim of diabetic treatment is to maintain blood glucose within or close to physiological normality, thereby minimizing the risk of long-term complications. It necessitates life-long monitoring of carbohydrate metabolism, energy expenditure and insulin or tablet dosage, and presumably demands a high level of understanding about diabetes together with successful social and psychological adjustment (1). There has been no definitive evidence to support an association between successful education and metabolic improvement. Various authors have emphasized the limitations of selecting increased knowledge as the sole criterion for success in diabetes education programs. The ability of individuals to adapt to the many stresses imposed by diabetes is determined, amongst other factors, by the coping strategies available to them (2).

A psychosocial approach is often needed to manage patients with non-insulin-dependent diabetes mellitus (NIDDM). It is well known that the incidence and control of the disorder are closely related to psychosocial aspects. Daily stress affects the incidence of diabetes mellitus significantly and may worsen diabetic control. Control may also be adversely affected by the number of life events and psychosocial factors. Therefore, both family and social support are very important for patients with NIDDM. Among the many types of such support, the advice or medical comment of doctors and medical staff should play the most important role in motivating the patients. It cannot be overemphasized that doctors should play a somewhat different role in diabetic treatment compared with that involved with other diseases (3-5).

This study assessed the factors affecting maintenance of good glycemic control following a comprehensive diabetes education program for inpatients. Patients' family function was assessed by the adaptability, partnership, growth, affection, and resolve (APGAR) scoring system. Social factors including family assistance as measured by the family APGAR score are particularly referred to in this study.

\section{Methods}

\section{Subjects, sites and design}

A total of 34 inpatients ( 22 men, 12 women) with type II diabetes who attended the diabetes education program at the Yukiguni-Yamato General Hospital over a period of 12 months from 1990 to 1991 were selected. The Yukiguni-Yamato General Hospital is a community hospital, serving a predominantly agricultural working class population. Table 1 lists the clinical characteristics of the 34 patients at the beginning of the study; some patients attended the diabetes education program accompanied by their spouse. The programs were held over five 
successive days. The content included general information on the causes, symptoms, treatment and complications of diabetes, general management principles, basic food information and dietary principles for diabetes, information on hypoglycemia, hyperglycemia and management of sick days, exercise, insulin types and their actions, oral hypoglycemic agents, interpretation of blood and urine results, use of alcohol, and selfmonitoring of blood glucose. Each topic was introduced with a brief videotape segment, and mutual discussion was encouraged. The diabetes team conducting the education program consisted of a diabetologist, nurse, dietitian and social worker.

Table 1. Clinical and Metabolic Characteristics of Study Subjects

\begin{tabular}{lcl}
\hline Characteristic & \multicolumn{3}{l}{} \\
Age (years) & 58.3 & $(27-73)$ \\
Sex (Men/women) & $22 / 12$ & \\
Duration of diabetes (years) & 4.7 & $(0-15)$ \\
Weight (kg) & 60.1 & $(40.2-99.0)$ \\
BMI on admission $\left(\mathrm{kg} / \mathrm{m}^{2}\right)$ & 23.9 & $(18.3-34.5)$ \\
FPG on admission $(\mathrm{mg} / \mathrm{dl})$ & 202 & $(122-484)$ \\
HbAlc on admission & 8 & $(5.9-15.0)$ \\
Family history of diabetes $(\%)$ & 8 & $(23.5)$ \\
Diabetic therapy $(\%)$ & & \\
$\quad$ Diet & 17 & $(50.0)$ \\
$\quad$ Oral hypoglycemic agents & 15 & $(44.1)$ \\
Insulin & 2 & $(5.9)$ \\
\hline
\end{tabular}

$\mathrm{N}: 34$. Values are means. Percentage or range from minimum to maximum are shown in parentheses.
Each patient enrolled into the program was initially treated in the clinic and was monitored after discharge.

A retrospective study design was used (6), and the study began between 6 and 12 months after discharge. At the beginning of the study, patients were classified into two groups, those with improved control and those with worsened control of diabetes. Control was defined in,terms of the rate of change of the glycosylated hemoglobin (HbAlc) value between the start of the study and discharge. A lowering of the HbAlc indicated improvement, and vice versa. Data for each patient were collected retrospectively from their medical records. Figure 1 illustrates the details of the study design.

\section{Measurements}

Metabolic control was assessed by HbAlc, using ion-exchange chromatography. The normal range for HbAlc by this assay was 4.0-5.5\%. Demographic data collected at admission were age, sex, family history of diabetes, and self-monitoring of blood glucose. Metabolic and medical data such as body-mass index (BMI), fasting plasma glucose (FPG), HbAlc, duration of diabetes, and change in treatment were also collected. Retinopathy, proteinuria, macroangiopathy, and medical treatment were recorded, and when relevant were also noted during admission. Social factors were family APGAR, smoking, alcohol use, income, and health beliefs, all of which were observed after discharge.

The family APGAR scoring system $(7,8)$ was particularly used to assess the family function of a patient. The family

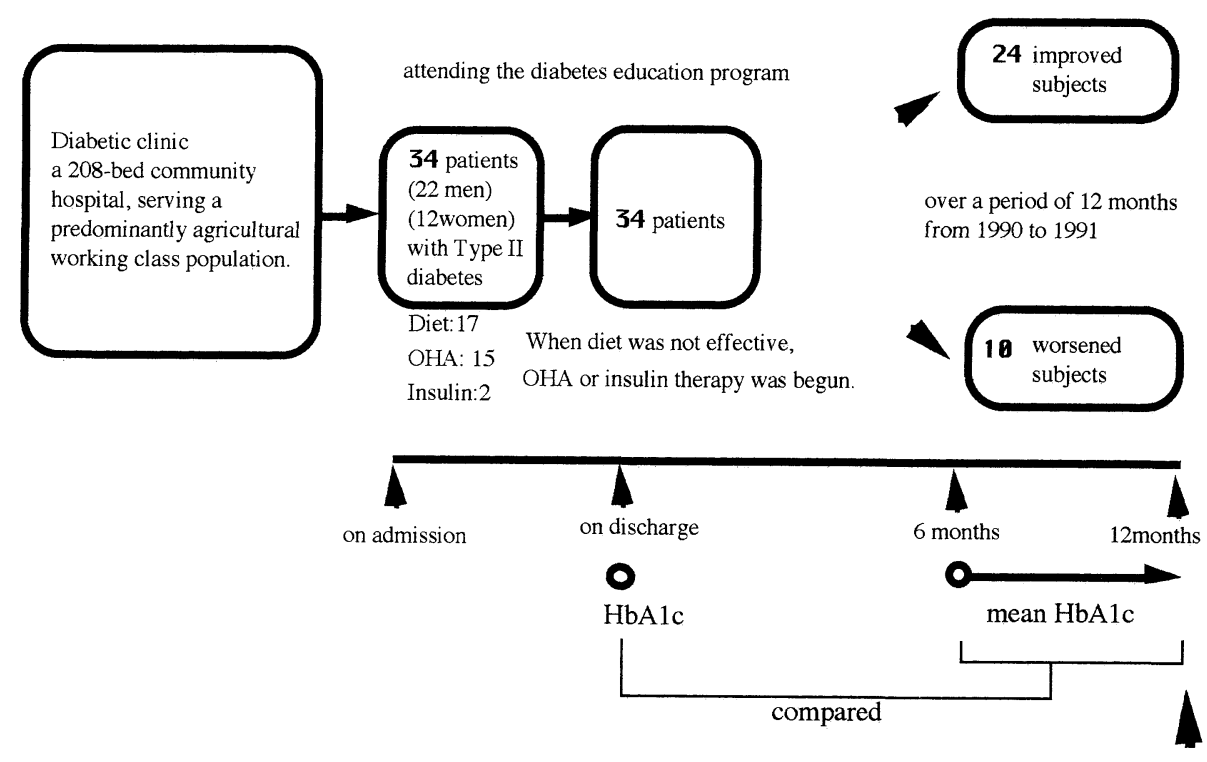

onset of the study

\begin{abstract}
improved subjects : relative improvement rate is greater than zero.
worsened subjects : relative improvement rate is less than zero.

Relative Improvement Rate $=\frac{\mathrm{HbA} 1 \mathrm{c} \text { on discharge }- \text { mean } \mathrm{HbA} 1 \mathrm{c} \text { from } 6 \text { to } 12 \text { months after discharge }}{\text { mean } \mathrm{HbA} 1 \mathrm{c} \text { from } 6 \text { to } 12 \text { months after discharge }}$
\end{abstract}

Fig. 1. The retrospective cohort study. 


\section{Effect of Social Factors on Metabolism}

APGAR scoring system (adaptability, partnership, growth, affection, and resolve) was described by Smilkstein in 1978 (7) as a brief screening test of family function for family physicians. It is a patient self-report method with scores of 0 to 2 given to each of the five items. The total APGAR score ranges from 0 to 10 , with a higher score representing a better family function. Belief about the cause of diabetes was also assessed by a patient self-report method.

In the statistical analyses, simple comparisons of factors were performed between the good control and poor control groups. Differences in patient characteristics between the two groups were analyzed by the Student's t test. Comparison of the family assistance score was carried out using the MannWhitney U test. Multiple regression analysis was applied where the relative rate of change in the HbAlc value within a single patient was a predictor variable. Explanatory variables were selected by integrating the correlations between them by stepwise regression analysis. An adjusted improvement in the APGAR score was estimated from the coefficient and standard error from multiple regression analysis. The Stat View statistical package (Abacus Concepts Inc., the U. S.) was utilized for the analysis, and two-tailed tests were used.

\section{Results}

Representative patients with good and bad APGAR scores are described below.

\section{Patient 1}

A 64-year-old man, who had been found to have diabetes mellitus 2 years prior to the study, visited our hospital for treatment of hyperglycemia in July 1990 . On admission, physical examination showed no abnormal findings; body height was $155.5 \mathrm{~cm}$ and body weight $54.5 \mathrm{~kg}$. Fasting plasma glucose was $146 \mathrm{mg} / \mathrm{dl}$, hemoglobin Alc 7.1\%, and fasting plasma insulin 10 $\mu \mathrm{U} / \mathrm{ml}$. His family APGAR score was 9 (adaptability, 2; partnership, 2; growth, 1; affection, 2; and resolve, 2), which was high, representing good family function. His health belief about the cause of diabetes was overeating. Hemoglobin Alc decreased smoothly over the course of treatment, as expected from the good APGAR score (Fig. 2).

\section{Patient 2}

A 59-year-old woman, a housewife, visited our hospital for treatment of hyperglycemia in June 1990. She had been diagnosed as having diabetes mellitus in 1988 and had been taking an oral hypoglycemic agent until admission. On admission, physical examination showed no abnormal findings; body height was $153.7 \mathrm{~cm}$ and body weight $49.8 \mathrm{~kg}$. Fasting plasma glucose was $122 \mathrm{mg} / \mathrm{dl}$, hemoglobin Alc 7.0\%, and urine C peptide $35.2 \mathrm{mg} / \mathrm{day}$. She had suffered stress due to a disturbed interpersonal relationship, and marital conflict. Her family APGAR score was 5 (adaptability, 1; partnership, 1; growth, 1; affection, 1 ; and resolve, 1), which was low, representing poor family function. Her health belief about the cause of diabetes was stress due to conflict with her husband, and cerebral infarction. The hemoglobin Alc improved transiently after intentional diet treatment during admission. However she subsequently got worse, showing the refractory nature of her poor APGAR score (Fig. 3).

The baseline clinical characteristics of the patients are summarized in Table 1. The clinical features of the two groups are shown in Tables 2 and 3. The HbAlc value on admission was significantly higher in the improved group than in the worsened group (9.19 \pm 2.42 vs $7.33 \pm 1.44, \mathrm{p}<0.05)$. The HbAlc on discharge was significantly higher in the improved group than the worsened group $(8.17 \pm 1.80$ vs $6.22 \pm 0.77, \mathrm{p}<0.01)$. The proportion of patients with alterations to therapy during admis-

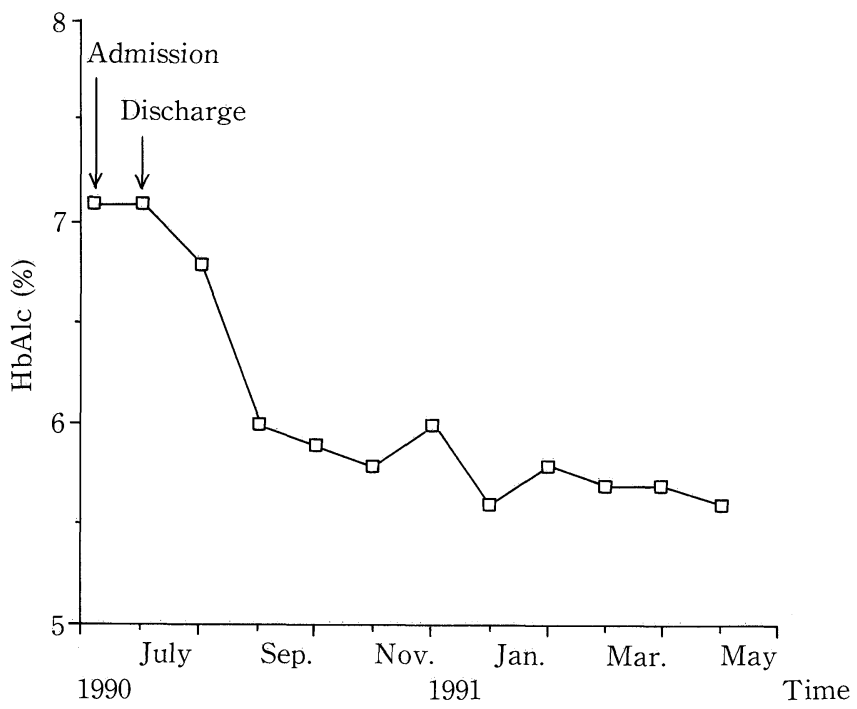

Fig. 2. Clinical course of patient 1 .

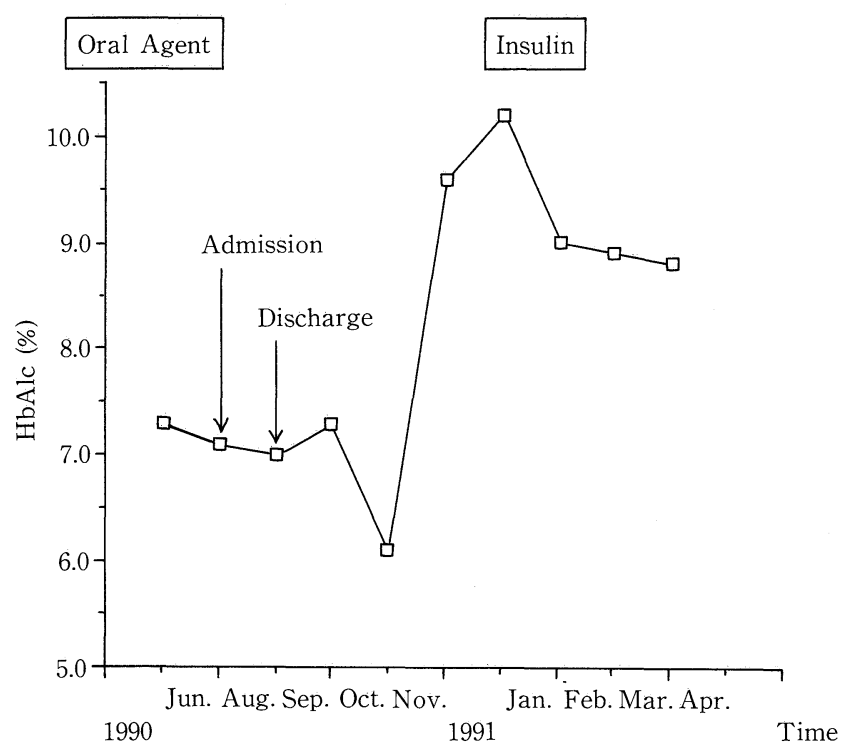

Oral Agent: gligenclamide $2.5 \mathrm{mg} /$ day, Insulin: intermediate human insulin 18 U/day.

Fig. 3. Clinical course of patient 2. 
Table 2. Baseline Characteristics of Demographic and Metabolic Aspects during Admission

\begin{tabular}{lcc}
\hline & $\begin{array}{c}\text { Improved group } \\
(\mathrm{N}=24)\end{array}$ & $\begin{array}{c}\text { Worsened group } \\
(\mathrm{N}=10)\end{array}$ \\
\hline Age (years) & $58.7 \pm 11.1$ & $50.6 \pm 10.7$ \\
Men/women & $14 / 10$ & $8 / 2$ \\
BMI on admission $\left(\mathrm{kg} / \mathrm{m}^{2}\right)$ & $23.69 \pm 3.97$ & $24.45 \pm 2.81$ \\
FPG on admission $(\mathrm{mg} / \mathrm{dl})$ & $215 \pm 69.9$ & $170.8 \pm 39.3$ \\
HbAlc on admission & $9.19 \pm 2.42$ & $7.33 \pm 1.14 *$ \\
HbAlc on discharge & $8.17 \pm 1.80$ & $6.22 \pm 0.77 *$ \\
Duration of diabetes (years) & $5.1 \pm 5.0$ & $3.5 \pm 3.9$ \\
Retinopathy & $5(20.8 \%)$ & $3(30 \%)$ \\
Proteinuria & $2(8.3 \%)$ & $1(10 \%)$ \\
Macroangiopathy & $3(12.5 \%)$ & $1(10 \%)$ \\
Diabetic therapy & & \\
$\quad$ Diet & $11(45.8 \%)$ & $6(60 \%)$ \\
Oral hypoglycemic agents & $11(45.8 \%)$ & $4(40 \%)$ \\
Insulin & $2(8.4 \%)$ & $0(0 \%)$ \\
\hline
\end{tabular}

Values are means \pm SD. Significance of difference from improved group: ${ }^{*} \mathrm{p}<0.05$. Data were analyzed comparing the two groups of patients by twotailed t-tests. If the relative change rate of $\mathrm{HbAlc}$ value was negative, then the patient was defined as being in the worsened group, vice versa. BMI: body mass index, FPG: fast plasma glucose, HbAlc: hemoglobin Alc.

sion was significantly higher in the improved group than in the worsened group ( $50 \%$ vs $10 \%, \mathrm{p}<0.05$ ). The family APGAR score was significantly higher in the improved group than in the worsened group $(8.0 \pm 1.9$ vs $5.4 \pm 2.2, \mathrm{p}<0.01)$. The family APGAR score and diabetic control are shown in Fig. 2. Other characteristics were very similar in each group.

These results were subjected to multiple regression analysis, in which a predictor variable was the relative rate of change in the HbAlc value. The variables in the model were FPG, HbAlc on discharge, BMI, family APGAR, health beliefs about diabetes control and change in therapy. The results of the multiple regression analysis are shown in Table 4 . A larger improvement in HbAlc occurred in patients who had a higher FPG on admission $(p<0.05)$, higher HbAlc on discharge $(p<0.001)$, and switched therapy from diet to hypoglycemic agents $(\mathrm{p}<0.05)$. Worsened diabetic control was found in patients who had erroneous health beliefs about the cause of diabetes $(\mathrm{p}<0.05)$.

The family APGAR score was higher in the improved group than in the other group $(\mathrm{p}<0.01$, Table 3$)$. A one-point increase in the APGAR score was estimated to contribute to the improvement of metabolic function by $2.2 \%$ (95\% confidence interval, -0.15 to 4.5 ), adjusting for all other factors in the model.

\section{Discussion}

The findings of the present study showed that family support could influence a patient's success in maintaining good control of diabetes. Although the FPG on admission and HbAlc on discharge significantly affected metabolic improvement, they were considered as adjusting factors in order to assess the social factors. All the subjects received comprehensive education about diabetes during admission, and this may have had an
Table 3. Comparison of the Psychosocial Aspects After Discharge between the Two Groups Classified by the Metabolic Improvement

\begin{tabular}{lcc}
\hline & $\begin{array}{c}\text { Improved group } \\
(\mathrm{N}=24)\end{array}$ & $\begin{array}{c}\text { Worsened group } \\
(\mathrm{N}=10)\end{array}$ \\
\hline Self monitoring of blood glucose & $4(16.7 \%)$ & $2(20 \%)$ \\
Smoking & $10(41.7 \%)$ & $6(60 \%)$ \\
Alcohol use & $12(50.0 \%)$ & $6(60 \%)$ \\
Lower annual income & $14(58.3 \%)$ & $4(40 \%)$ \\
Alternation of therapy & $12(50.0 \%)$ & $1(10 \%)$ \\
Overeating (cause of diabetes) & $15(62.5 \%)$ & $5(50 \%)$ \\
Alcohol use (cause of diabetes) & $5(20.8 \%)$ & $3(30 \%)$ \\
Overwork (cause of diabetes) & $3(12.5 \%)$ & $0(0 \%)$ \\
Inherent (cause of diabetes) & $0(0.0 \%)$ & $1(10 \%)$ \\
Erroneous health belief & $1(4.7 \%)$ & $1(10 \%)$ \\
Family history of diabetes & $6(25.0 \%)$ & $2(20 \%)$ \\
Family APGAR Score & $8.0 \pm 1.956$ & $5.4 \pm 2.171 * *$ \\
\hline
\end{tabular}

Values are means \pm SD. Percentage is shown in parentheses. Significance of difference from improved group: ${ }^{*} \mathrm{p}<0.05, * * \mathrm{p}<0.01$.

Table 4. Effects on the HbAlc Improvement by Multiple Regression Analysis

\begin{tabular}{lrcll}
\hline Variable & Coefficient & Std. Err. & t-Value & p-value \\
\hline HbAlc on discharge & 10.215 & 2.02 & 5.056 & 0.0001 \\
Alternation to HGA & 24.452 & 9.898 & 2.47 & 0.0204 \\
FPG on admission & 0.122 & 0.056 & 2.168 & 0.0395 \\
Unique interpretation & -25.757 & 12.389 & 2.079 & 0.0476 \\
Hypoglycemic agent & -11.767 & 6.329 & 1.859 & 0.0744 \\
APGAR & 2.172 & 1.186 & 1.831 & 0.0786 \\
Complication & 7.036 & 6.654 & 1.057 & 0.3001 \\
\hline
\end{tabular}

HbAlc: hemoglobin Alc, HGA: hypoglycemic agent, FPG: fast plasma glucose, APGAR: family APGAR score.

underlying effect, as shown by previous studies (9-11). These have also indicated the need for a more effective approach to diabetes control. Thus, education may not be sufficient by itself. The present study showed the necessity of family support in addition to education. Korhonen (12) showed that any diabetes education program that fails to address changes in attitudes and motivation will be unlikely to produce long-term improvements in diabetic control. He also suggested that patient compliance was a more critical factor in determining diabetes control than either disease duration or C-peptide reactivity (CPR) to glucagon stimulation. Becker (13) has also suggested that compliance increases as a function of perceived severity of the illness and perceived susceptibility to its complications based on the Health Belief Model.

The present study showed that an extensive education program did not necessarily lead to a change in social factors such as family assistance, indicating poor compliance with the education program. Even though every patient participated in the program, we observed a great difference in social factors after discharge. In addition, there was some association between the extent of family assistance and improvement in metabolic function. This implies that family assistance is helpful in bringing about improvement even if patients receive an 


\section{Effect of Social Factors on Metabolism}

extensive program of education about diabetes in the clinic.

The study method used had several inherent weaknesses, which require discussion. Firstly, the sample size may have been too small to allow a definitive conclusion to be made about social function during the education program. It may be impossible to adjust the social function result for so many factors with the relatively small number of subjects. A larger number of subjects will be studied as a next step. Secondly, some critics may point to the study design. A retrospective cohort design is relatively weak in proving any causal relationship between family assistance and metabolic improvement. A prospective investigation of intervention to promote family assistance would allow a more conclusive result to be obtained. Thirdly, minor modification of the statistical analysis may be required. Relative change in rate as a predictor variable is restricted between $-100 \%$ and $100 \%$. The arcsine transformation might be applied to these values, although the result did not change much, and interpretation would be easier without such a transformation.

Despite these weak points, this study did illustrate the importance of family assistance at home for diabetic patients. Identifying resources, educating the family to best utilize these resources, and helping the family to mobilize them should be a function borne by the medical staff. A diabetic education program augmented by family assistance will be helpful for the management of diabetes.

\section{References}

1) Dunn SM, Beeney LJ, Hoskins PL, Turtle JR. Knowledge and attitude change as predictors of metabolic improvement in diabetes education.
Soc Sci Med 31: 1135, 1990.

2) Wulson L, Rand A, Jacobson M. Management of stress and glycemic control in diabetes. Intern Med Specialist 9: 100, 1988.

3) DesMarchais JE, Jean P, Castonguay LG. Training psychiatrists and family doctors in evaluating interpersonal skills. Med Educ 24: 376, 1990.

4) Bryant LH, McFarland KF, Michels P. The patient/physician relationship in the management of diabetes mellitus. South Carolina Med Assoc p389, 1990.

5) Schwartz LS, Coulson LR, Toovy D, et al. A biopsychosocial treatment approach to the management of diabetes mellitus. Gen Hosp Psychiat 13: 19, 1991.

6) Dawnson-Saunders B, Trapp RG. Basic and Clinical Biostatistics. Appleton \& Lange, Connecticut, 1990, p. 10.

7) Smilkstein G. The family APGAR: A proposal for a family function test and its use by physicians. J Fam Pract 6: 1231, 1978.

8) Smilkstein G, Ashworth C, Montana D. Validity and reliability of the family APGAR as a test of family function. J Fam Pract 15: 303, 1982.

9) White N, Carnahan J, Nugent CA, Iwaoka T, Dodson MA. Management of obese patients with diabetes mellitus: comparison of advice education with group management. Diabetes Care 9: 490, 1986.

10) Rabkin SW, Boyko E, Wilson A, Streja DA. A randomized clinical trial comparing behavior modification and individual counseling in the nutritional therapy of non-insulin-dependent diabetes: comparison of the effect on blood sugar, body weight, and serum lipid. Diabetes Care 6: 50, 1983.

11) Campbell LV, Barth R, Gosper JK, Jupp JJ, Simons LA, Chisholm DJ. Impact of intensive educational approach to dietary change in NIDDM. Diabetes Care 13: 841, 1990.

12) Korhonen T. A controlled trial on the effects of patient education in the treatment of insulin-dependent diabetes. Diabetes Care 6: 256, 1983.

13) Becker MH. Sociobehavioral Determinants of Compliance. in: Compliance with Therapeutic Regimens, Sackett D, Haynes R, Eds. Johns Hopkins Press, London, 1976. 